\title{
LIVER ABSCESSES: A 10-YEAR VINNYTSYA UNIVERSITY STUDY
}

\author{
Volodymyr Shaprynskyi ${ }^{1}$ \\ surgery1@vnmu.edu.ua \\ Viktor Makarov ${ }^{1}$ \\ Vasylysa Suleimanova ${ }^{1}$ \\ Yevhen Shaprynskyi ${ }^{1}$ \\ Stepan Skalskyi ${ }^{1}$ \\ ${ }^{1}$ Department of Surgery No. 1 \\ National Pirogov Memorial Medical University \\ 56 Pirogov str., Vinnytsya, Ukraine, 21018
}

\section{Abstract}

According to MEDLINE database there were about 1278 papers on liver abscess published in a period from 2001 to 2015.

The aim of the study is to improve liver abscess treatment results comparing minimally invasive and traditional operative techniques.

Materials and methods. 137 patients were included in the study and divided on two comparison groups. Traditional methods were used for the treatment of 66 participants of the control group (48.2\%). For 71 patients $(51.8 \%)$ of the general group the mini-invasive drainages were predominating.

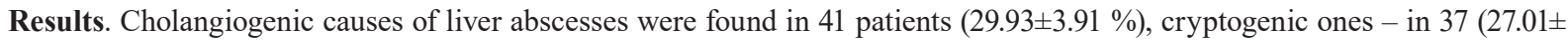
$\pm 3.79 \%)$, haematogenous causes - in $29(21.17 \pm 3.49 \%)$, contact ones - in $16(11.68 \pm 2.75 \%)$, posttraumatic ones - in $11(8.03 \pm 2.32 \%)$ and purulent destruction of metastases - in $3(2.19 \pm 1.25 \%)$.

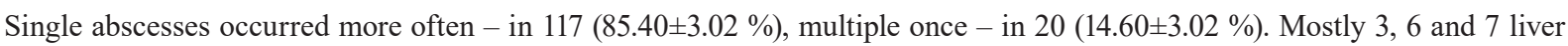
segments were damaged - 19 (13.88 $\pm 2.95 \%), 35$ (25.55 $\pm 3.73 \%), 44(32.12 \pm 3.99 \%)$.

In control group, the abscess drainage via laparotomy was performed on 58 patients $(87.88 \pm 4.02 \%$ of 66 ones $)$ versus $21(29.58 \pm 5.42 \%$ of 71 ones) in general group. Percutaneous drainage was used in $8(12.12 \pm 4.02 \%)$ and in $44(61.97 \pm 5.76 \%)$ cases respectively. 6 or $8.45 \pm 3.30 \%$ laparoscopic interventions were used only in the general group. Finally, mini-invasive drainages were applied in the greater part of general group - 50 (70.42 $\pm 5.42 \%)$ versus 8 ones (12.12 $\pm 4.02 \%)$ in control group.

Conclusions. Minimally invasive liver abscess drainages showed a significant reduction of postoperative complications from $24.24 \pm 5.27 \%$ in the control group to $12.66 \pm 3.95 \%$ in the general group, shortening of hospital terms from $14.6 \pm 1$ in control to $5.2 \pm$ \pm 0.8 days and decreasing of mortality from $7.58 \pm 3.26 \%$ to $2.82 \pm 1.96 \%$.

Keywords: liver abscess, mini-invasive surgery, laparoscopic liver surgery, drainage of liver abscess, puncture of liver abscess.

DOI: $10.21303 / 2504-5679.2020 .001122$

\section{Introduction}

In recent years, the amount of liver abscesses (LA) has been significantly increasing [1, 2]. It has obviously been demonstrated in numerous studies.

According to MEDLINE database in a 2001-2015 period there were 1278 documents published on LA. Scopus search has shown the similar results -1303 records [3].

LA is the most frequent abdominal organs suppuration with an incidence from 5 to 20 in 100000 hospitalizations [3, 4]. Increasing of LA is connected with innovative diagnostic capabilities in medicine, such as ultrasound, computerized tomography and magnetic resonance imaging $[5,6]$. The incidence of gallstone disease and its complications have also been growing $[7,8]$. The LA reasons include portal vein and biliary retrograde infection, sepsis and other cryptogenious suppurations [9]. At the same time, authors explain the increasing of LA because of constantly increase of hepatobiliary mini-invasive surgical procedures [10, 11]. Nowadays, at the same time 
there are changes in the sensitivity of LA microflora to antibacterial and antiseptic drugs and presence of many multiresistant germs $[1,10]$.

Mortality rate among the patients with LA is between $4.5 \%$ to $31 \%$, but it is decreasing thanks to modern and timely diagnostic efficacy methods, effective antimicrobial agents and mini-invasive surgical procedures with ultrasound or computerized tomography guidance [12, 13]. In this article, we are presenting our 10-year treatment experience of LA.

The aim of the work. To improve treatment results of patients with liver abscesses admitted to Vinnytsya regional hospital comparing mini-invasive methods and traditional operative techniques.

\section{Materials and methods}

This study was conducted at National Pirogov Memorial Medical University and Regional Clinical Hospital named after N. I. Pirogov, Vinnytsia, Ukraine from January 2008 to December 2018.

All 137 hospitalized patients with a confirmed LA diagnosis (based on clinical, laboratory-biochemical, radiological and instrumental presentations) were divided into two groups (general - 71 persons, operated from 2014 to 2018, and control - 66 ones, operated from 2008 to 2013). 66 patients of control group (48.2\%) were treated using traditional methods such as external drainage, fenestration, pericystectomy, segmental liver resection, hemigepatectomy. Among 71 patients $(51.8 \%)$ of general group, preference was given to mini-invasive surgical interventions. Invasive procedures included aspiration, percutaneous drainage and surgical interventions. Both groups were representative by gender, age, causes, localization of LA and women were dominating. The age of the patients ranged from 26 to 83 years, with the median age 59 years old.

Before entering the patient in the study protocol, a written voluntary agreement to participate in this study was obtained in accordance with the WMA Declaration of Helsinki - Ethical Principles for Medical Research Involving Human Subjects. The study protocol was approved by the Local Ethics Committee (LEC) of the Vinnytsya National Pirogov Memorial Medical University, protocol №8, dated 05.10.2017).

Most often, the disease occurred in middle-aged people and elderly (81.6\%) ones. Females accounted for 1.39 times more than males. Moreover, in the age over 60 years the incidence of LA among women was 1.2 times more frequent than among men. After 75 years, the LA incidence was approximately the same in both genders.

The duration of the disease, ranging from the appearance of the first clinical signs to the admission at a surgical hospital lasted from 4 days to 7 months. Patients with a disease period from 7 days to 1 month were predominant (62.1\% and $63.4 \%$ in both groups). The 7 -month period was established in 1 patient whose disease was recurrent.

Concomitant pathology was equally common in both groups and was presented in $117(85.4 \%)$ patients. Almost a half of patients had a combination of several diseases. Undoubtedly, comorbidities had a negative impact on the course of the essential disease.

\section{Results}

The study of the LA causes showed that cholangiogenic causes of liver abscesses were found in 41 patients $(29.93 \pm 3.91 \%)$, cryptogenic ones - in $37(27.01 \pm 3.79 \%)$, hematogenous causes - in $29(21.17 \pm 3.49 \%)$, contact ones - in $16(11.68 \pm 2.75 \%)$, posttraumatic ones - in $11(8.03 \pm 2.32 \%)$ and purulent destruction of metastases - in $3(2.19 \pm 1.25 \%)$. The majority of patients with LA presented fever $-100 \%$, abdominal pain under the right rib arch $92.70 \pm 2.22 \%$, chills $-31.39 \pm 3.96 \%$, decrease appetite $-46.72 \pm 4.26 \%$, weight loss $-62.77 \pm 4.13 \%$, jaundice $-16.79 \pm 3.19 \%$ cases.

Laboratory tests showed leukocytosis with shifting to the left, moderate anemia, increasing of SRI, hypoproteinemia, hyperbilirubinemia, increasing of liver enzymes as well as hypercoagulation.

The general condition of 87 (63.5\%) patients was severe $-54.74 \pm 4.25 \%$ or extremely severe $-8.76 \pm 2.42 \%$. The rest 50 patients $(36.5 \%)$ had the medium degree of severity $-29.20 \pm 3.88 \%$ or satisfactory condition $-7.30 \pm 2.22 \%$. 
LA were grouped as small ones $(\leq 5 \mathrm{~cm}, \mathrm{n}=57$ or $41.61 \pm 4.21 \%)$, large abscesses $(5 \mathrm{~cm}$ to $10 \mathrm{~cm}, \mathrm{n}=72$ or $52.55 \pm 4.27 \%)$ and giant abscesses $(>10 \mathrm{~cm}, \mathrm{n}=8$ or $5.84 \pm 2.00 \%)$. The bigger size was taken into account in case of irregular LA border.

As a rule, LA affected almost all liver segments, though, the 3rd (13.88 $\pm 2.95 \%)$, 6th $(25.55 \pm$ $\pm 3.73 \%)$ and 7 th segments $(32.12 \pm 3.99 \%)$ were more often affected. 20 patients $(14.60 \pm 3.02 \%)$ suffered from multiple LA in both liver lobes.

In both groups the volume of LA was from 10 to $200 \mathrm{ml}$. All patients were operated on as it is presented in Table 1.

Table 1

The kinds of interventions in patients with LA

\begin{tabular}{|c|c|c|c|c|c|c|c|c|c|}
\hline \multirow[b]{2}{*}{ No. } & \multicolumn{3}{|c|}{ Laparotomy open approaches } & \multicolumn{3}{|c|}{ Percutaneous drainage } & \multicolumn{3}{|c|}{ Laparoscopic approaches } \\
\hline & $\begin{array}{c}\text { Kind of } \\
\text { intervention }\end{array}$ & $\begin{array}{c}\text { Control } \\
\text { group }\end{array}$ & $\begin{array}{l}\text { General } \\
\text { group }\end{array}$ & $\begin{array}{c}\text { Kind of } \\
\text { intervention }\end{array}$ & $\begin{array}{l}\text { Control } \\
\text { group }\end{array}$ & $\begin{array}{l}\text { General } \\
\text { group }\end{array}$ & $\begin{array}{c}\text { Kind of } \\
\text { intervention }\end{array}$ & $\begin{array}{l}\text { Control } \\
\text { group }\end{array}$ & $\begin{array}{c}\text { General } \\
\text { group }\end{array}$ \\
\hline 1 & External drainage & 48 & 7 & $\begin{array}{l}\text { Punction } \\
\text { needle aspi- } \\
\text { ration }\end{array}$ & - & 6 & $\begin{array}{l}\text { Punction } \\
\text { needle aspi- } \\
\text { ration }\end{array}$ & - & 1 \\
\hline 2 & Fenestration & 5 & 5 & $\begin{array}{c}\text { Percutaneous } \\
\text { drainage }\end{array}$ & 8 & 38 & $\begin{array}{l}\text { External } \\
\text { drainage }\end{array}$ & - & 3 \\
\hline 3 & Pericystectomy & 2 & 4 & & - & - & Fenestration & - & 2 \\
\hline 4 & $\begin{array}{l}\text { Resection of } \\
\text { multiple segments } \\
\text { with abscesses }\end{array}$ & 2 & 3 & & - & - & & - & - \\
\hline 5 & Hemigepatectomy & 1 & 2 & & - & - & & - & - \\
\hline & $\mathrm{N}=137$ & 58 & 21 & & 8 & 44 & & - & 6 \\
\hline
\end{tabular}

In control group, the operation of liver abscess drainage via laparotomy was performed in 58 cases $(87.88 \pm 4.02 \%$ of 66 patients) versus 21 (29.58 $\pm 5.42 \%$ of 71 patients) in the general group. Percutaneous drainage of abscesses $-8(12.12 \pm 4.02 \%)$ and $44(61.97 \pm 5.76 \%)$ respectively. Laparoscopic operations 6 or $8.45 \pm 3.30 \%$ took place only in the general group and included external percutaneous drainage in 3 or $4.23 \pm 2.39 \%$ cases, fenestration - in 2 or $2.82 \pm 1.41 \%$, puncture-needle aspiration in 1 or $1.41 \pm 1.40 \%$.

The complications were presented with suppuration of postoperative wound $-4(6.06 \pm$ $\pm 2.94 \%)$ in control group versus $1(1,41 \pm 1.40 \%)$ in general group, exudative pleuritis on the right $-4(6.06 \pm 2.94 \%)$ versus $3(4,23 \pm 2.39 \%)$, bile leakage $-2(3.03 \pm 2.11 \%)$ versus $2(2.82 \pm$ $\pm 1.41 \%)$, pneumonia $-4(6.06 \pm 2.94 \%)$ versus $2(2.82 \pm 1.41 \%)$, early adhesive intestinal obstruction $-2(3.03 \pm 2.11 \%)$ versus $1(1,41 \pm 1.40 \%)$ respectively. The length of hospital stay was also reduced from $14.6 \pm 1$ in control to $5.2 \pm 0.8$ days in general group $(\mathrm{p}<0.05)$. $(\mathrm{p}<0.05)$.

7 (5.1\%) patients died -5 or $7.58 \pm 3.26 \%$ in control and 2 or $2.82 \pm 1.96 \%$ in general group

\section{Discussion}

Nowadays there are no well established guidelines for treatment of patients with LA. According to recent LA studies, different authors present different treatment approaches. Recent articles have offered puncture needle aspiration as a first-line approach because it is simple, comfortable and cheap $[8,14]$. Ultrasound-guided needle aspiration of LA followed by pipe drainage is safe and shows good treatment results $[15,16]$. In our opinion, percutaneous drainage is a more effective and curable method for LA, particularly when its sizes exceed $5 \mathrm{~cm}$ in diameter. It has been proved by some authors who reported that being larger than $5 \mathrm{~cm}$ LA had a higher rate of curative affec- 
tion if it is treated with antibiotics only [17]. Other scientists wrote that bigger part of their patients with LA (47\%) were subjected to a percutaneous drainage or were treated using open drainage (34\%) [18]. Recent research (2016) has reported about conservative antibiotics treatment of patients with LA in $28 \%$ cases, $39.3 \%$ patients received percutaneous drainage and $32.7 \%$ underwent surgical incision and drainage [9]. Other publication also said about antibiotic therapy alone for the treatment of multiple hepatic abscesses [19]. Instead, our results have shown no one patient with only antibiotics, the amount of LA percutaneous drainage reached $62 \%$ with decreasing of open surgical operations. Our mind is divided by many authors who supported the fact that only aggressive operative techniques should be received as more effective ones $[12,20]$. We want to emphasize that using of laparoscopic approaches for LA in our study showed good results without postoperative complications or mortality.

The limitations of the research. The study included all patients older than 18 years old with the diagnosis of LA from January 2008 to December 2018. The diagnosis of LA confirmed through ultrasound investigation and clinical picture.

The further research plan includes the study of widening the indications for percutaneous drainage with ultrasound and CT support to develop effective guidelines for LA.

\section{Conclusions}

The minimally invasive surgical drainage techniques in patients with LA significantly reduced $(\mathrm{p}<0.05)$ the number of postoperative complications from $24.24 \pm 5.27 \%$ in the control group to $12.66 \pm 3.95 \%$ in the general group, shortening of inpatient terms from $14.6 \pm 1$ in the control group to $5.2 \pm 0.8$ days in the general group and decreasing of mortality rate from $7.58 \pm 3.26 \%$ to $2.82 \pm 1.96 \%$ respectively.

The using of laparoscopic approaches for LA showed good results without postoperative complications or mortality.

\section{Conflict of interest}

There is no conflict of interest.

\section{References}

[1] Premathilake, P. N. S., Kularatne, W. K. S., Jayathilake, J. P. K., Senadhira, S. D. N. (2018). Klebsiella pneumoniae liver abscess: a case report. Journal of Medical Case Reports, 12(1). doi: http://doi.org/10.1186/s13256-018-1924-4

[2] Serraino, C., Elia, C., Bracco, C., Rinaldi, G., Pomero, F., Silvestri, A. et. al. (2018). Characteristics and management of pyogenic liver abscess. Medicine, 97 (19), e0628. doi:10.1097/md.0000000000010628

[3] González-Alcaide, G., Peris, J., Ramos, J. M. (2017). Areas of research and clinical approaches to the study of liver abscess. World Journal of Gastroenterology, 23 (2), 357. doi: http://doi.org/10.3748/wjg.v23.i2.357

[4] Czerwonko, M. E., Huespe, P., Bertone, S., Pellegrini, P., Mazza, O., Pekolj, J. et. al. (2016). Pyogenic liver abscess: current status and predictive factors for recurrence and mortality of first episodes. HPB, 18 (12), 1023-1030. doi: http://doi.org/10.1016/ j.hpb.2016.09.001

[5] Lin, A. C.-M., Yeh, D. Y., Hsu, Y.-H., Wu, C.-C., Chang, H., Jang, T.-N., Huang, C.-H. (2009). Diagnosis of pyogenic liver abscess by abdominal ultrasonography in the emergency department. Emergency Medicine Journal, 26 (4), 273-275. doi: http:// doi.org/10.1136/emj.2007.049254

[6] Zerem, E., Hadzic, A. (2007). Sonographically Guided Percutaneous Catheter Drainage Versus Needle Aspiration in the Management of Pyogenic Liver Abscess. American Journal of Roentgenology, 189 (3), W138-W142. doi: http://doi.org/10.2214/ ajr.07.2173

[7] Yoon, J. H., Kim, Y. J., Kim, S. I. (2019). Prognosis of liver abscess with no identified organism. BMC Infectious Diseases, 19 (1). doi: http://doi.org/10.1186/s12879-019-4131-Z

[8] Cai, Y.-L., Xiong, X.-Z., Lu, J., Cheng, Y., Yang, C., Lin, Y.-X. et. al. (2015). Percutaneous needle aspiration versus catheter drainage in the management of liver abscess: a systematic review and meta-analysis. HPB, 17 (3), 195-201. doi: http://doi.org/ 10.1111/hpb.12332

[9] Du, Z.-Q., Zhang, L.-N., Lu, Q., Ren, Y.-F., Lv, Y., Liu, X.-M., Zhang, X.-F. (2016). Clinical Charateristics and Outcome of Pyogenic Liver Abscess with Different Size: 15-Year Experience from a Single Center. Scientific Reports, 6 (1). doi: http:// doi.org/10.1038/srep35890 
[10] Sharma, A., Mukewar, S., Mara, K. C., Dierkhising, R. A., Kamath, P. S., Cummins, N. (2018). Epidemiologic Factors, Clinical Presentation, Causes, and Outcomes of Liver Abscess: A 35-Year Olmsted County Study. Mayo Clinic Proceedings: Innovations, Quality \& Outcomes, 2 (1), 16-25. doi: http://doi.org/10.1016/j.mayocpiqo.2018.01.002

[11] Lardière-Deguelte, S., Ragot, E., Amroun, K., Piardi, T., Dokmak, S., Bruno, O. et. al. (2015). Hepatic abscess: Diagnosis and management. Journal of Visceral Surgery, 152 (4), 231-243. doi: http://doi.org/10.1016/j.jviscsurg.2015.01.013

[12] Chen, S. C., Tsai, S. J., Chen, C. H., Huang, C. C., Lin, D. B., Wang, P. H. et al. (2008). Predictors of mortality in patients with pyogenic liver abscess. The Netherlands Journal of Medicine, 66, 196-203.

[13] Chen, C.-H., Wu, S.-S., Chang, H.-C., Chang, Y.-J. (2014). Initial presentations and final outcomes of primary pyogenic liver abscess: a cross-sectional study. BMC Gastroenterology, 14 (1). doi: http://doi.org/10.1186/1471-230x-14-133

[14] Wong, W.-M., Wong, B. C. Y., Hui, C. K., Ng, M., Lai, K. C., Tso, W. K. et. al. (2002). Pyogenic liver abscess: Retrospective analysis of 80 cases over a 10-year period. Journal of Gastroenterology and Hepatology, 17 (9), 1001-1007. doi: http://doi.org/ 10.1046/j.1440-1746.2002.02787.x

[15] Mohan, S., Talwar, N., Chaudhary, A., Andley, M., Ravi, B., Kumar, A. (2006). Liver abscess: a clinicopathological analysis of 82 cases. International Surgery, 91, 228-233.

[16] Yu, S. C. H., Ho, S. S. M., Lau, W. Y., Yeung, D. T. K., Yuen, E. H. Y., Lee, P. S. F., Metreweli, C. (2004). Treatment of pyogenic liver abscess: Prospective randomized comparison of catheter drainage and needle aspiration. Hepatology, 39 (4), $932-938$. doi: http://doi.org/10.1002/hep.20133

[17] Chan, D. S. G., Archuleta, S., Llorin, R. M., Lye, D. C., Fisher, D. (2013). Standardized outpatient management of Klebsiella pneumoniae liver abscesses. International Journal of Infectious Diseases, 17 (3), e185-e188. doi: http://doi.org/10.1016/ j.ijid.2012.10.002

[18] Alvarez Pérez, J. A., González, J. J., Baldonedo, R. F., Sanz, L., Carreño, G., Junco, A. et. al. (2001). Clinical course, treatment, and multivariate analysis of risk factors for pyogenic liver abscess. The American Journal of Surgery, 181 (2), $177-186$. doi: http://doi.org/10.1016/s0002-9610(00)00564-x

[19] Alvarez, J. A., González, J. J., Baldonedo, R. F., Sanz, L., Carreño, G., Jorge, J. I. (2001). Single and Multiple Pyogenic Liver Abscesses: Etiology, Clinical Course, and Outcome. Digestive Surgery, 18 (4), 283-288. doi: http://doi.org/10.1159/000050153

[20] Abusedera, M. A., El-Badry, A. M. (2014). Percutaneous treatment of large pyogenic liver abscess. The Egyptian Journal of Radiology and Nuclear Medicine, 45 (1), 109-115. doi: http://doi.org/10.1016/j.ejrnm.2013.11.005 